\title{
CAROTID PLAQUE AND TYPE 2 DIABETES MELLITUS.
}

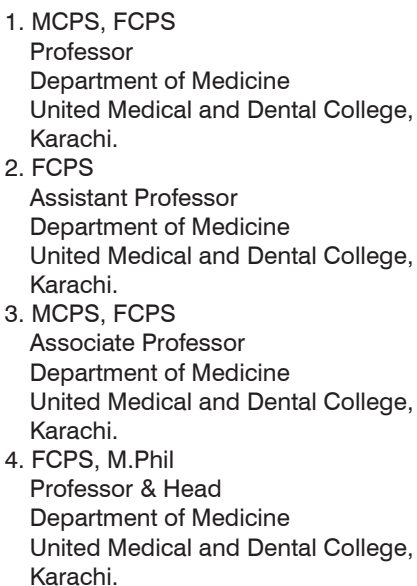

Correspondence Address:

Dr. Farhat Bashir

40-B, $1^{\text {st }}$ East Street, Phase 1

DHA, Karachi.

drfarharbashir@gmail.com

Article received on:

19/04/2018

Accepted for publication:

15/10/2018

Received after proof reading:

22/05/2019

\section{INTRODUCTION}

As the epidemic of diabetes mellitus extends throughout the world and is being projected to affect around 370 million people by the year $2030^{1}$, the related complications are also expected to increase. Along with the control of hyperglycemia, early diagnosis and treatment of its manifold complications is seen as a major challenge to the management of this disease. In areas of the world where the life style modifications and early management of cardio-metabolic risk factors is in place they have been able to reduce the mortality caused by cardiovascular disease. ${ }^{2}$ Diabetes mellitus, due to atherosclerosis, is a major risk factor for cardiovascular disease like coronary artery disease, cerebrovascular disease and peripheral vascular disease.

Carotid Doppler ultrasound is a reliable and noninvasive method to measure CIMT, presence

\begin{abstract}
Farhat Bashir ${ }^{1}$, Ayesha Nageen ${ }^{2}$, Saera Sohail Kidwai ${ }^{3}$, Jamal Ara ${ }^{4}$
ABSTRACT: Atherosclerosis is the basic cause of macrovasular complications of diabetes (CIMT) and presence cerebrovascular accidents. The purpose of this study was to find the association of carotid plaque cases of type 2 diabetes mellitus. All subjects underwent Carotid Doppler ultrasonography. The demographic, anthropometric, clinical and laboratory data was collected and analyzed through SPSS ver.20.0. The relationship of carotid plaque with different atherosclerotic variables was assessed by Student's t-test and Chi-square test. P-value of $<0.5$ was considered significant. presence of plaque was associated with duration of diabetes, presence of hypertension, BMI, diastolic blood pressure, total cholesterol, triglyceride levels and CIMT. Conclusion: We need to focus on management of the multiple metabolic abnormalities associated with diabetes mellitus in order to prevent atherosclerosis and its associated cardiovascular disease.
\end{abstract}

Key words: Carotid Plaque, Cardio-Metabolic, CVA, Ischemic heart disese, Type 2 Diabetes Mellitus. mellitus. Professional Med J 2019; 26(6):913-918. DOI: 10.29309/TPMJ/2019.26.05.3595

of carotid plaque and degree of stenosis in the carotid arteries. This procedure provides a safe assessment of atherosclerosis not only in the carotid circulation but also gives an estimation of atherosclerosis in the coronary and peripheral circulation. ${ }^{3,4}$ Atherosclerosis in the carotid artery leads to increased carotid intima-media thickness, carotid plaque formation and carotid stenosis. The degree of carotid stenosis and plaque vulnerability are related to the greater risk of stroke. ${ }^{5}$ Indeed they can independently predict cerebrovascular accidents. ${ }^{6}$ Presence of carotid plaque shows a stronger association with cardiovascular risk compared with diffuse CIMT increase. $^{7}$ The echogenicity of the plaque also determines the vulnerability of the plaque and thus the risk of cerebrovascular accidents. ${ }^{8,9}$

Many factors are associated with an increased CIMT and presence of plaque. These include age, 
male gender, diabetes mellitus, hypertension, dyslipidemia, obesity and smoking. Carotid plaque is frequently found in diabetic patients. ${ }^{10}$ In this study we assess the association of carotid plaque with various cardio-metabolic risk factors in type 2 diabetes mellitus.

\section{SUBJECTS AND METHODS}

A cross-sectional study was designed and all adult cases of type 2 diabetes mellitus presenting to the Medical Out-patient Department of Creek General Hospital, Karachi, were enrolled in the study. Patients with type 1 diabetes mellitus and those with secondary diabetes were excluded from the study. The duration of the study was one year from June 2015 to May 2016. The study was approved by the Ethical Review Committee of the institution. At the time of recruitment, consent was taken and a proforma including history, examination findings, anthropometric measurements and the laboratory results were recorded. The investigations included fasting and random blood glucose levels, HbA1c and fasting lipid profile. Carotid Doppler studies were performed for all the study participants. A single radiologist performed the procedure using a linear transducer of $7.5 \mathrm{~Hz}$ in B mode (Toshiba Nemio 35). CIMT was measured at the far wall of the Common Carotid Artery and was taken as

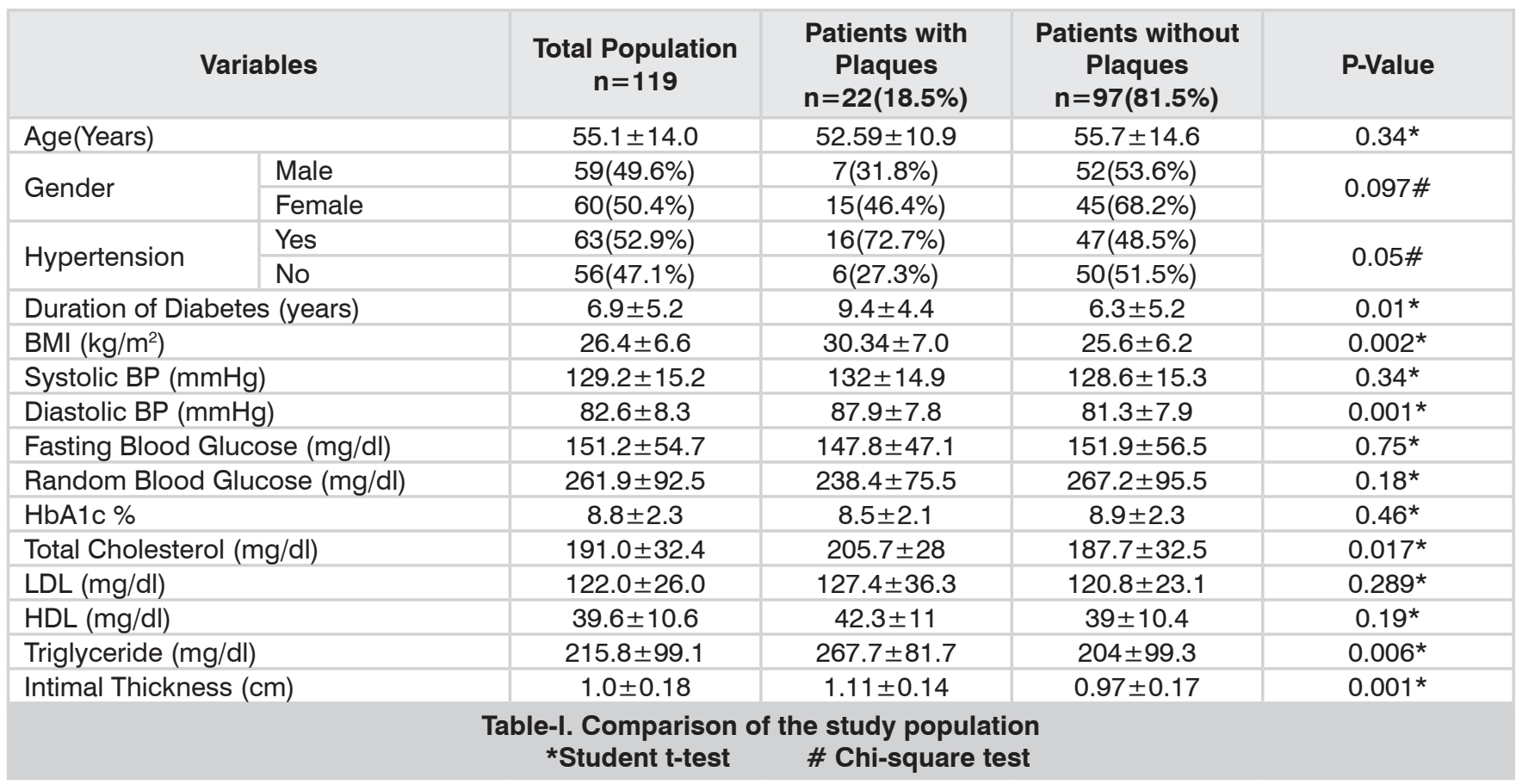




\section{DISCUSSION}

A person with diabetes has a three times greater probability of death because of a cardiovascular cause compared to a person without diabetes mellitus. ${ }^{11}$ Atherosclerosis can be assessed by both coronary and carotid angiography or non-invasively by Carotid Doppler scanning. Carotid atherosclerosis is detected by this procedure through measuring CIMT and carotid plaques. Carotid intima media thickness increases in diabetic patients due to the atherosclerotic process. Diabetes mellitus leads to atherosclerosis because of the multiple metabolic changes that are part of the diabetic complex. Atherosclerosis itself is an inflammatory process while the hyperglycemia in diabetes mellitus also contributes to the inflammation and results in a higher cardiovascular mortality. ${ }^{12}$

Inpatients withtype2diabetesaging, hypertension, duration of diabetes, hyperglycemia, dyslipidemia, and smoking have been identified as significant risk factors for stroke. ${ }^{13,14,15}$ As diabetes mellitus is a metabolic syndrome, the multiple entities associated with it all lead to thickening of the carotid wall as evidenced by increased CIMT in these patients. Duration of diabetes, systolic blood pressure and total cholesterol was found to have a stronger relationship with CIMT in persons with type 2 diabetes mellitus in a study. ${ }^{14}$ There is also evidence that presence of multiple risk factors will lead to greater increase in CIMT. ${ }^{3}$ As mentioned earlier this is the case in subjects with diabetes mellitus as they have multiple cardiometabolic risk factors present concurrently.

Our study showed $18.5 \%$ of the diabetic patients had a carotid plaque. A study showed $28 \%$ of diabetic patients were having carotid plaques. The prevalence of carotid plaques increased with time in these patients. ${ }^{16}$ Another study revealed carotid plaques in $77 \%$ of diabetic patients. But this study was in patients older than 65 years which may be a factor for such a high percentage of plaque presence. ${ }^{10}$

A study revealed that association between atherosclerosis as assessed by ankle brachial index and carotid artery stenosis was similarly associated with diabetes in both genders. ${ }^{17}$ There was no gender based difference seen in our study either. This may be due to the fact that most of the population was elderly. At older age females lose the protective effect of gender on atherosclerosis. But other studies have shown that CIMT was closely associated with age, gender and smoking. ${ }^{18}$

LDL cholesterol is seen to be associated with CIMT. ${ }^{19}$ In our preceding study CIMT showed a relationship with both total cholesterol and LDL. ${ }^{14}$ But the current study shows that carotid plaque was only associated with total cholesterol and triglyceride levels. All fractions of the blood lipids are associated with cardiovascular disease. Different fractions have been observed to be deranged in type 2 diabetes mellitus in different studies.

Patients with diabetes are at greater risk of suffering from a stroke associated with more morbidity and mortality as compared to nondiabetic individuals. ${ }^{20}$ Studies in prediabetes have shown significant association of $\mathrm{HbA} 1 \mathrm{c}$ with CIMT indicating that it may successfully predict vascular disease. ${ }^{21}$ This was also confirmed in patients with metabolic syndrome. ${ }^{22} \mathrm{HbA1c}$ is also associated with presence of microvascular complications in diabetic patients. ${ }^{23}$ Multiple studies have shown the association of CIMT with different glycemic parameters in patients with diabetes and impaired glucose tolerance..$^{24,25,26}$

Patients in our study did not demonstrate any association of blood glucose levels or glycated hemoglobin percentages with presence of carotid plaque as it is the duration of exposure to the atherogenic effect of diabetes rather than specific glucose levels.

We demonstrated an association of BMI to presence of carotid plaque. There have been varying results associated with obesity and its relationship with obesity. Some studies have not demonstrated an association ${ }^{4,27}$ while others show a relationship of obesity with carotid atherosclerosis. ${ }^{28}$ 
The process of atherosclerosis is observed initially as increased CIMT the progression of which leads to plaque formation and vascular narrowing. Therefore it was observed in our study that a higher CIMT was significantly associated with carotid plaque. Carotid plaques are also sources of thromboemboli leading to both higher coronary and cerebral vascular diseases.

This study was a continuation of previous studies showing the relationship of CIMT with different cardio-metabolic risk factors in diabetic patients. ${ }^{14}$ This study was focused on presence of plaque as this would be related to a more severe disease indicating greater atherosclerosis. The patients with carotid plaques are more prone to develop cardiovascular complications. We need to know which cardio-metabolic risk factors are associated with the presence of plaques. Our study showed a significant relationship of hypertension especially diastolic blood pressure, increased BMI and increased total cholesterol and triglyceride levels with presence of plaque.

Our management of the diabetic patient will thus be focused on weight optimization, control of blood pressure and management of dyslipidemia in addition to glycemic control. So the management of these multiple factors may play a role to prevent progression of atherosclerosis and even its' regression. Interestingly CIMT has been used to assess the response to therapeutic intervention in patients with atherosclerosis. ${ }^{29,30,31}$

\section{CONCLUSION}

Atherosclerosis occurs early and is extensive in diabetes mellitus due to clustering of multiple risk factors in this condition. Management of these co-existing abnormalities is required to prevent or delay cardiovascular disease in these patients. Copyright@ 15 Oct, 2018.

\section{REFERENCES}

1. Bashir F, Khan ZU, Qureshi S, Seetlani NK, Sheikh Z. Prevalence of hypovitaminosis $D$ in type 2 diabetes mellitus and its relationship with glycemic control. J Liaquat Uni Med Health Sci. 2016; 15(02): 83-88.

2. Roth GA, Forouzanfar MH, Moran AE, Barber R, Nguyen $\mathrm{G}$, Feigin VL, et el. Demographic and epidemiologic drivers of global cardiovascular mortality. N Engl J Med 2015; 372:1333-1341.

3. Matsumoto K, Sera $\mathrm{Y}$, Nakamura $\mathrm{H}$, et al. Correlation between common carotid arterial wall thickness and ischemic stroke in-patients with type 2 diabetes mellitus. Metabolism 2002; 51:244-247.

4. Vemmos KN, Tsivgoulis G, Spengos K, et al. Common carotid artery intima-media thickness in patients with brain infarction and intra-cerebral hemorrhage. Cerebrovasc Dis 2004; 17:280-86.

5. Halliday A, Mansfield A, Marro J, Peto C, Peto R, Potter J, Thomas D. Prevention of disabling and fatal strokes by successful carotid end-arterectomy in patients without recent neurological symptoms: Randomised controlled trial. Lancet. 2004; 363:1491-1502.

6. Saad M, Zakarya S, Abu-Hegazy M, El Shafaee M, Abdelkhaleq A. Predictors of atherosclerotic burden in type 2 DM. Egypt J Neurol Psychiat Neurosurg. 2011: 48(2):103-110.

7. Ebrahim S, Papacosta O, Whincup P, etal. Carotid plaque, intima-media thickness, cardiovascular risk factors, and prevalent cardiovascular disease in men and women: The British Regional Heart Study. Stroke 1999; 30: 841-50.

8. Ostling G, Hedblad B, Berglund G, Goncalves I. Increased echolucency of carotid plaques in patients with type 2 diabetes. Stroke. 2007; 38: 2074-2078.

9. Sigurdardottir V, Fagerberg B, Hulthe J. Preclinical atherosclerosis and inflammation in 61-year-old men with newly diagnosed diabetes and established diabetes. Diabetes Care. 2004; 27: 880-884.

10. Rajala U, Laakso M, Paivainsalo M, Suramol, KeinainenKiukaanniemi S. Blood pressure and atherosclerotic plaques in carotid, aortic and femoral arteries in elderly Finns with diabetes mellitus or impaired glucose tolerance. Journal of Human Hypertension 2005; 19: 85-91.

11. Stamler J, Vaccaro $O$, Neaton JD, Wentworth D. Diabetes, other risk factors, and 12-yr cardiovascular mortality for men screened in the Multiple Risk Factor Intervention Trial. Diabetes Care. 1993; 16: 434-444.

12. Temelkova-Kurktschiev TS, Koehler C, Leonhardt W, et al. Increased intima-media thickness in newly developed type 2 diabetes. Diabetes Care 1999; 22: 333-38.

13. Lee EJ, Kim HJ, Bae JM, Kim JC, Han HJ, et al. Relevance of common carotid intima-media thickness and carotid plaque as risk factors for ischemic stroke in patients with type 2 diabetes mellitus. Am J Neuroradiol 2007; 28: 916-19. 
14. Bashir F, Nageen A, Kidwai SS, Ara J. Carotid intimamedia thickness and cardiometabolic risk factors in Pakistani type 2 diabetics. Saudi J Health Sci 2017; 6:145-50.

15. Kawamori R, Yamasaki $\mathrm{Y}$, Matsushima $\mathrm{H}$, et al. Prevalence of carotid atherosclerosis in diabetic patients. Diabetes Care 1992; 15:1290-94.

16. Lundman P, Keech AC, Griffiths K, Pillai A, Celemajor DS. New carotid plaque formation is very common in adult patients with type 2 diabetes mellitus. Diabet Med 2005; 22(3): 355-356.

17. Shah B, Rockman CB, Guo Y, Chesner J, et al. Diabetes and vascular disease in different arterial territories diabetes care 2014;37:1636-1642.

18. Kong C, Elatrozy T, Anyaoku V, Robinson S, Richmond W, Elkeles RS. Insulin resistance, cardiovascular risk factors and ultrasonically measured early arterial disease in normotensive type 2 diabetic subjects. Diabetes Metab RES Rev 2000; 16:448-53.

19. Folsom AR, Chambless LE, Duncan BB, Gilbert AC, Pankow JS. The atherosclerosis risk in communities study investigators: Prediction of coronary heart disease in middle-aged adults with diabetes. Diabetes Care 2003; 26: 2777-2784.

20. Dorigo W, Pulli R, Pratesi G, Fargion A, Marck J, Innocenti AA, Pratesi C. Early and long-term results of carotid endarterectomy in diabetic patients. Journal of Vascular Surgery 2011; 53(1): 44-52.

21. Venkataraman V, Amutha A, Anbalagan VP, Deepa M, Anjana RM, Unnikrishnan R, et al. Association of glycated hemoglobin with carotid intimal medial thickness in Asian Indians with normal glucose tolerance. Journal of Diabetes and its Complications. 2012; 26: 526-530.

22. Bobbert T, Mai K, Fischer-Rosinsky A, Pfeiffer AF, Spranger J. HbA1c is associated with intimalmedia thickness in individuals with normal glucose tolerance. Diabetes Care 2010; 33: 203-204.

23. Stratton IM, Adler AI, Neil HA, Matthews DR, Manley $\mathrm{SE}$, Cull CA, et al. Association of glycemia with macrovascular and microvascular complications of type 2 diabetes (UKPDS 35): Prospective observational study. BMJ 2000; 321: 405-412.
24. Folsom AR, Eckfeldt JH, Weitzman S, Ma J, Chambless LE, Barnes RW, et al. Relation of carotid artery wall thickness to diabetes mellitus, fasting glucose and insulin, body size, and physical activity. Atherosclerosis Risk in Communities (ARIC) Study Investigators. Stroke 1994; 25: 66 -73.

25. Vitelli LL, Shahar E, Heiss G, McGovern PG, Brancati FL, Eckfeldt G, etal. Glycosylated hemoglobin level and carotid intimal-medial thickening in non diabetic individuals: The Atherosclerosis Risk in Communities Study. Diabetes Care 1997; 20: 14541458.

26. Temelkova-Kurktschiev TS, Koehler C, Henkel E, Leonhardt W, Fuecker K, Hanefeld M. Post challenge plasma glucose and glycemic spikes are more strongly associated with atherosclerosis than fasting glucose or HbA1c level. Diabetes Care 2000; 12: 1830-1834.

27. Taniguchi A, Nakai Y, Fukushima M, Teramura S, Hayashi $\mathrm{R}$, Hama K, et al. Ultrasonography assessed carotid atherosclerosis in Japanese type 2 diabetic patients: Role of nonestrified fatty acids. Metabolism. 2002; 51 : 539-43.

28. Takayuki N, Naohisa H, Hideo O, Shin-Ichiro I, Camelia RB, Tsutomu T, et al. Smoking, fasting serum insulin, and obesity are the predictors of carotid atherosclerosis in relatively young subjects. Angiology. 2007; 58: 677-84.

29. Touboul PJ, Labreuche J, Vicaut E, etal. Carotid intima media thickness, plaques, and Framingham risk score as independent determinants of stroke risk. Stroke 2005; 36: 1741-45.

30. Beishuizen ED, VandeRee MA, Jukema JW, etal. Twoyear statin therapy does not alter the progression of intima-media thickness in patients with type 2 diabetes without manifest cardiovascular disease. Diabetes Care 2004;27: 2887-92

31. Hedblad B, Wikstrand J, Janzon L, et al. Low-dose metoprolol CR/XL and fluvastatin slow progression of carotid intima-media thickness: Main results from the Beta-Blocker Cholesterol-Lowering asymptomatic plaque study (BCAPS). Circulation 2001; 103:1721-26. 


\begin{tabular}{|c|c|c|c|}
\hline \multicolumn{4}{|c|}{ AUTHORSHIP AND CONTRIBUTION DECLARATION } \\
\hline Sr. \# & Author-s Full Name & Contribution to the paper & Author $=s$ Signature \\
\hline 1 & & $\begin{array}{l}\text { Concept, Data collection, } \\
\text { Statistical analysis,Write up. }\end{array}$ & Fantatsadmin \\
\hline 2 & Ayesha Nageen & $\begin{array}{l}\text { Data collection, Statistical } \\
\text { analysis, Literature review. }\end{array}$ & \\
\hline 3 & $\begin{array}{l}\text { Saera Sohail Kidwai } \\
\text { Jamal Ara }\end{array}$ & $\begin{array}{l}\text { Literature review, Statistical } \\
\text { analysis. } \\
\text { Concept, Final write up. }\end{array}$ & \\
\hline
\end{tabular}

